\title{
Audit of Anaesthetic Management of Eclamptic Patients for Caesarean Section in the North-Eastern, Nigeria
}

\author{
Adamu Sadiq Abubakar, ${ }^{1,3}$, Mohammed Bukar ${ }^{2}$, Aliyu Usman El-Nafaty ${ }^{2,4}$, \\ Mohammed Bala Audu², Gyadale Abdulhamid ${ }^{3}$, Babagana Mulima ${ }^{1}$, Ahmed Muhammed ${ }^{1}$ \\ ${ }^{1}$ Department of Anaesthesia and Intensive Care, University of Maiduguri Teaching Hospital, Maiduguri, Nigeria \\ ${ }^{2}$ Department of Obstetrics and Gynaecology, University of Maiduguri Teaching Hospital, Maiduguri, Nigeria \\ ${ }^{3}$ Department of Anaesthesia and Intensive care, Federal Teaching Hospital, Gombe, Gombe state, Nigeria \\ ${ }^{4}$ Department of Obstetrics and Gynaecology, Federal Teaching Hospital, Gombe, Gombe state, Nigeria \\ Email address: \\ adamusadiq48@gmail.com (A. S. Abubakar)
}

\section{To cite this article:}

Adamu Sadiq Abubakar, Mohammed Bukar, Aliyu Usman El-Nafaty, Mohammed Bala Audu, Gyadale Abdulhamid, Babagana Mulima, Ahmed Muhammed. Audit of Anaesthetic Management of Eclamptic Patients for Caesarean Section in the North-Eastern, Nigeria. Journal of Anesthesiology. Vol. 3, No. 2, 2015, pp. 6-9. doi: 10.11648/j.ja.20150302.11

\begin{abstract}
Background: Objectives: To determine the clinical characteristics of the obstetric patients that were complicated with eclampsia and compare it to all uncomplicated obstetrics patients (non-eclampsia) that had caesarean sections, determine the technique of anaesthesia and the anaesthetic management of the eclamptic patients in our centres. Materials and Methods: This was a retrospective case-control multi-centered study of eclamptic patients that had caesarean sections under anaesthesia in the University of Maiduguri Teaching Hospital, Maiduguri, Borno State and Federal Teaching Hospital, Gombe, Gombe State North-eastern Nigeria over four year period from January, 2011 to December, 2014. Results: A total of two hundred and seventy three (273) eclamptic patients made up 158(57.88\%) and 115(42.12\%) from University of Maiduguri Teaching Hospital, Maiduguri and Federal Teaching Hospital, Gombe respectively that had caesarean sections under various types of anaesthesia during the study period, which represents $17.42 \%$ of total caesarean sections $(1,567$ patients $)$ and $1.87 \%$ of all deliveries (14,611 patients) during the 4-year period. Most of the eclamptic patients had GA (87.18\%). The case fatality rate for eclampsia managed in ICU was $14.65 \%$.However; the overall case fatality for eclampsia was $18.31 \%$. Conclusion: The commonest anaesthesia employed for eclamptics was general anaesthesia, this was because most of the patients that presented to our centres were either unconscious or had late presentation. We therefore, recommend regular public enlightenment on eclampsia in our environment and also to encourage a team work among the team members.
\end{abstract}

Keywords: Anaesthetic Management, Eclamptics, Caesarean Section, North-Eastern, Nigeria

\section{Introduction}

Eclampsia is one of the most common emergencies encountered by the Anaesthetists. Any pregnant woman presenting with a convulsion in an emergency setting should be taken as eclampsia until proven otherwise. It is defined as the occurrence of one or more generalized convulsions and/or coma in the setting of pre-eclampsia and in the absence of other neurologic conditions before, during, or after labour. ${ }^{1}$

The differential diagnosis includes epilepsy, cerebral infarction, cerebral haemorrhages, cerebral venous thrombosis, cerebral oedema, malignant hypertension, benign and malignant cerebral tumours, cerebral abscess, viral, bacterial, parasitic infestations, hyponatremia, hypocalcaemia, hypoglycaemia, and hyperglycaemia etc. ${ }^{2,3}$

The risk factors for eclampsia include among others nulliparity, multiple gestation, molar pregnancy, pre-existing hypertension or renal diseases, previous severe preeclampsia or eclampsia, non-immune hydrops-foetalis and systemic lupus erythematous. ${ }^{4}$

The major complications of eclampsia include HELLP syndrome, intrauterine growth retardation, abruption placentae, neurologic deficits, aspiration pneumonitis, DIC, pulmonary oedema, renal failure and cardiac arrest. ${ }^{5}$

The role of the anaesthetist in eclampsia is to help obstetrician to control and prevent further convulsions, control blood pressure, establish a clear airway, prevent major complications, to provide labour analgesia and 
anaesthesia for caesarean section and also in the critical care management when indicated.

The objective of this study therefore, was to audit the clinical characteristics of the eclamptics and compared it to all non-eclamptic patients that had caesarean sections, determine the technique of anaesthesia among the two groups and the outcome of anaesthetic management of the eclamptic patients over four year period in our centres.

\section{Materials and Methods}

This was a retrospective multi-centered study of eclamptic patients that had caesarean sections at the University of Maiduguri Teaching Hospital, Maiduguri, Borno State and Federal Teaching Hospital, Gombe, Gombe state, Nigeria over four year period from January, 2011 to December, 2014.The University of Maiduguri Teaching Hospital is one of the teaching hospitals in the North-eastern Nigeria with only one consultant anaesthetist and five registrars, while Federal Teaching Hospital, Gombe is the other teaching hospital in the same zone with a consultant Anaesthetist and seven registrars.

Patients admitted within the above period were identified through their case notes, the theatre records books and ICU records; and all eligible patients were identified. The patient records were then screened to ensure that when admitted, they were pregnant or within 42 days of termination of pregnancy. ${ }^{6}$ For all women who had eclampsia before, during and after delivery and had caesarean section were selected as the case group, while all others who had caesarean section from other indications are considered as the control group.

The protocol for the study was approved by the Ethical committees of the two hospitals and no patient intervention was involved.

Each patient record was reviewed in detail and data retrieved for analysis included socio-demographic parameters, co-morbidities, obstetrics features (antepartum history, weeks of gestation, antenatal abnormalities and vital signs).

For each patient, data on the technique of anaesthesia, haemodynamic parameters of the patients, postoperative disposal of the patients and the outcomes of the management were recorded and analyzed.

Results were expressed as numbers and percentages, mean and standard deviation (SD) where appropriate. Comparisons of the clinical characteristics were made of the all complicated obstetrics with eclampsia and uncomplicated cases as the controls that had Caesarean section using Student's t test and $\chi 2$ test where appropriate. A $P$-value of less than 0.05 was considered statistically significant. Statistical analyses were performed using EPI-INFO version 3.5.1 (CDC, Atlanta, Georgia, USA).

\section{Results}

A total of two hundred and seventy three (273) eclamptic patients made up $158(57.88 \%)$ and $115(42.12 \%)$ from the University of Maiduguri Teaching Hospital, Maiduguri and Federal Teaching Hospital, Gombe respectively that had Caesarean sections under anaesthesia during the study period, which represents $17.42 \%$ of total caesarean sections $(1,567$ patients) and $1.87 \%$ of all deliveries (14,611 patients) during the 4-year period.

Most of the patients were full time housewives $189(69.23 \%)$. Others were civil servants 56(20.51\%) and students $28(10.26 \%)$

The age ranged from 15-49 years with a mean of $27.92 \pm$ 6.37. Seventeen patients $(6.23 \%)$ were of advanced maternal age ( $>35$ years). The mean parity was $4.86 \pm 3.62$ and the mean gestational age was $36.32 \pm 6.29$; range was $26-44$ weeks. Fifty six $(20.51 \%)$ of the patients had a pre-morbid medical condition.

When compared with the control, the age of the patients and the birth weight there were no significant differences in the cases and the control with the $\mathrm{P}=0.59$ and 0.57 respectively, while the proportion of booked patients, gestational age at delivery and parity were significant as compared between the cases and the control as shown in table 1 . The controls were also more educated and gainfully employed compared to the cases and the differences are statistically significant $(\mathrm{P}=0.00,0.05)$.

The commonest technique of anaesthesia employed was general anaesthesia in $258(87.18 \%)$ and for the control general anaesthesia was used in 234 (18.08\%)

Table 3 showed the changes in the haemodynamic status between the complicated obstetrics cases with eclampsia (cases) and compared to the uncomplicated obstetrics cases that had Caesarean section (control).

Most of the patients in the case group were transferred to the ICU in 203(74.36\%), while most of the patients in the control group were transfer to the obstetrics ward for further management in $1,136(87.80 \%)$ in the postoperative period.

The total number of patients that were transferred out of the ICU were $163(59.71 \%$ ) and the number of patients that died in the ICU were $40(14.65 \%)$ within the period under review as showed in table 4 .

Table 1. comparison of the socio-demographic characteristics and risk factors of patients.

\begin{tabular}{llllll}
\hline S/N & Factors & Cases (Eclamptic) & Control (Non-eclamptic) & t test $/ \boldsymbol{X}^{\mathbf{2}}$ & P-value \\
\hline 1 & Age & $27.92 \pm 6.37$ & $27.33 \pm 6.11$ & 0.08 & 0.57 \\
2 & Parity & $4.86 \pm 3.62$ & $3.54 \pm 6.07$ & 137.48 & 0.00 \\
3 & Gestation age & $36.32 \pm 6.29$ & $34.33 \pm 6.11$ & 93.43 & 0.33 \\
4 & Baby weight & $2.49 \pm 6.26$ & $2.05 \pm 5.78$ & 44.35 & 0.00 \\
5 & Estimated blood loss & $689 \pm 6.38$ & $589 \pm 2.40$ & 7.11 & 0.00 \\
6 & Pre-morbid condition & $20.51 \%$ & $5.55 \%$ & 27.33 & 0.04 \\
7 & Booked Ante-natal care & $36.72 \%$ & $28.55 \%$ & 12.62 & 0.00 \\
8 & Gainfully employed & $20.85 \%$ & $38.52 \%$ & 13.03 \\
9 & Education rate & $35.06 \%$ & $51.47 \%$ & 0.05 \\
\hline
\end{tabular}


Table 2. Comparison of the choice of anaesthetic technique among the study group.

\begin{tabular}{lllll}
\hline Technique & Cases & Control & $\boldsymbol{X}^{2}$ & P-value \\
\hline General anaesthesia (GA) & $238(87.18 \%)$ & $234(18.08 \%)$ & 122.59 & 0.00 \\
Spinal anaesthesia (SA) & $2(0.73 \%)$ & $936(72.33 \%)$ & 667.11 & 0.00 \\
Epidural anaesthesia (EA) & $19(6.96 \%)$ & $112(8.66 \%)$ & 270.77 & 0.00 \\
Combined Spinal-epidural (CSEA) & $13(4.76 \%)$ & $12(0.09 \%)$ & 0.25 & 0.62 \\
Local anaesthesia (LA) & $1(0.37 \%)$ & & & \\
Total & $273(100 \%)$ & $1,294(100 \%)$ & & \\
\hline
\end{tabular}

Table 3. Comparison of the haemodynamic changes between the study groups.

\begin{tabular}{llll}
\hline & Parameters & Cases(Mean \pm SD) & Control(Mean \pm SD) \\
\hline Pre-operative & PR (per minute) & $85.32 \pm 2.46$ & $80.11 \pm 4.67$ \\
& SBP(mmHg) & $118.51 \pm 2.96$ & $114.92 \pm 6.78$ \\
& DBP(mmHg) & $78.65 \pm 3.56$ & $78.28 \pm 4.69$ \\
& MAP(mmHg) & $91.94 \pm 2.67$ & $68.12 \pm 3.67$ \\
Intra- operative changes & PR (per minute) & $74.32 \pm 2.46$ & 0.61 \\
& SBP(mmHg) & $112.45 \pm 2.34$ & 0.43 \\
& DBP(mmHg) & $68.45 \pm 3.12$ & $119.46 \pm 7.73$ \\
Post- operative changes & MAP(mmHg) & $77.70 \pm 1.75$ & $79.34 \pm 9.23$ \\
& PR (per minute) & $78.29 \pm 2.49$ & $86.81 \pm 3.30$ \\
& SBP(mmHg) & $116.34 \pm 3.46$ & $89.44 \pm 4.75$ \\
& DBP(mmHg) & $71.34 \pm 3.54$ & 0.29 \\
& MAP(mmHg) & $88.34 \pm 1.81$ & 0.47 \\
\hline
\end{tabular}

Table 4. Outcome of patient's management based on the site of disposal of the eclamptic patients.

\begin{tabular}{llll}
\hline Wards & Discharge no. (\%) & Death no. (\%) & Total no. (\%) \\
\hline Obstetric ward & $16(5.86 \%)$ & $2(0.73 \%)$ & $18(6.59 \%)$ \\
High dependency unit & $44(16.12 \%)$ & $8(2.93 \%)$ & $52(19.05 \%)$ \\
Intensive care unit & $163(59.71 \%)$ & $40(14.65 \%)$ & $203(74.36 \%)$ \\
Total & $223(81.69 \%)$ & $50(18.31 \%)$ & $273(100 \%)$ \\
\hline
\end{tabular}

\section{Discussion}

Our study found that most of the eclamptic patients had general anaesthesiafor caesarean section. This may not be unconnected with the fact that most of these patients were referred from private hospitals or from secondary health centres; hence the delay in presentations to the hospital. .Moreover, they usually presented to the hospital in the state of unconsciousness following series of convulsions at home or in the private hospitals that necessitated urgent optimization and emergency Caesarean section. We equally found that only $36.72 \%$ of these patients that had ante-natal care due to either poverty or ignorance.

In an earlier study in the 1970s and 1980s, which showed a low level of education among pregnant women in the developing countries, our study showed that $35.06 \%$ and $51.47 \%$ of the eclamptic and non-eclamptic patients had at least secondary school education respectively. Although many are educated, the majority of the patients $(62.23 \%)$ still remain as housewives. This may not be unconnected to the high rate of unemployment and cultural factors which discourages married women from public service.

It was reported by Parthasarathyetal ${ }^{7}$ that general anaesthesia is the preferred anaesthesia in an unconscious, obtunded patients with evidence of an increased in intracranial pressure (ICP).This anaesthesia was achieved with an opioid and relaxant technique with deliberate hyperventilation. However, $34 \%$ of these patients had regional anaesthesia (spinal, epidural or combined spinal epidural anaesthesia) when they were found to be fully conscious, seizure free with stable vital signs and no signs of raised ICP. The policy in our hospitals remain that for eclamptic patient who presented with unconsciousness, general anaesthesia is the technique of choice. However, if the patients are conscious and no contra-indications to regional anaesthesia then regional anaesthesia is considered over general anaesthesia.

Moodleyetal $^{8}$ found no differences in maternal and neonatal outcomes when comparing epidural versus general anaesthesia for caesarean section in conscious women with eclampsia. Spinal anaesthesia with low-dose bupivacaine with fentanyl is a good alternative. Safety of spinal anaesthesia has been studied by Razzaque et al, ${ }^{9}$ who concluded that spinal anaesthesia is safer than general anaesthesia for low segment caesarean section in eclamptic patients; however, he has not stated the level of consciousness of the studied patients.

It has been recommended by American Society of Regional Anaesthesia ${ }^{10}$ that a low-dose aspirin therapy is not a contra-indication to regional technique rather the platelet 
count of the patient. Regional anaesthesia is considered safer when the platelet count is more than 75,000 per micro litre. However, when the platelet count is less than 50,000 it is generally considered a contra-indication to regional anaesthesia. Women with pre-eclampsia are at increased risk of thrombo-embolic diseases. Before delivery, all patients should have anti-embolic stockings or low-molecular weight heparin while immobile. Following delivery, low molecular weight heparin (dose adjusted on early pregnancy weight) should be given daily until the patient is fully mobile (seven days if delivered by CS). Low molecular weight heparin should not be given until 4-6 hours after spinal anaesthesia. An epidural catheter should be left in place for at least 12 hours after low molecular weight heparin administration. Following removal of the epidural catheter low molecular weight heparin should not be given for 4-6 hours to avoid haematomaformation. ${ }^{10}$

In this study we found that there were no significant changes with the haemodynamic parameters of the two groups of patients in the preoperative period as all our patients were promptly and adequately optimized before surgical interventions. However, we observed that the control have more stable vital signs compared to the case group. This may be due to the swinging vital signs seen in the eclamptic patients. We observed that both groups are stable in the postoperative period but stability was better with the control group and this determined our choice of patient's disposal.

The mortality rate of the patients that were admitted into our intensive care units within the period under review was similar to previous studies. ${ }^{11,12,13}$ However, these were lower than the $50 \%$ and $60 \%$ reported by Osinaike et al ${ }^{14}$ and Dao et al. ${ }^{15}$ It was also higher than the $6 \%$ reported by Natalie et $\mathrm{al}^{16}$ from a developed country.

These lower mortality rates may be because of the earlier recourse to ICU care in our centres and also some improvement in the standard of care received by the patients while in the ICU. However, the mortality rate can be further reduced with better equipment, improvement in the strength of anaesthesia manpower and regular training and re-training of ICU staff in the management of the critical care of eclamptic patients.

\section{Conclusion}

The definitive management of eclamptic patient is delivery of the foetus. However, it is inappropriate to deliver an unstable mother even if there is foetal distress. Once the seizures are controlled, severe hypertension treated and hypoxia corrected, delivery can be expedited. General anaesthesia is the frequent choice of anaesthesia in our centres when the patients are unconscious or if there were contra-indications to regional anaesthesia. Most of our patients were managed in the ICU at the postoperative period.

We therefore, recommend regular public enlightenment on eclampsia in our environment and also to encourage a team work among the team members.

\section{References}

[1] Cunningham FG, Leveno KJ, Bloom SL, Haulth JC, Rouse DJ, Spong CY. Williams Obstetrics. Pregnancy Hypertension. $23^{\text {rd }}$ Chap 34, New York: McGraw-Hill; 2010:706-56.

[2] Kaplan PW, Repke, JT. Eclampsia. Neuro Clin 1994; 12: $565-$ 82.

[3] Sibai BM, Eclampsia. In: Goldstein PJ, editors. Neurologic Disorder of Pregnancy, $2^{\text {nd }}$ ed. Mount Kisco, New York: Futura Publishing Company; 1992: 1-24.

[4] Sibai BM. Eclampsia. Maternal -perinatal outcome in 254 consecutive cases. Am J Obstet Gynecol. 1990; 163: 1049-55.

[5] Mattar F, Sibai BM. Eclampsia VIII. Risk factors for maternal morbidity. Am J Obstet Gynecol. 2000; 182: 307-12.

[6] Knaus WA, Draper EA, Wagner DP, Zimmerman JE. APACHE- A severity of disease classification system. Crit Care Med. 1995; 13: 818-829.

[7] Parthasarathy S, Hemanth Kumar VR, Sripriya R, Ravishankar M. Anesthetic management of a patient presenting with eclampsia. Anesth Essay Res 2013; 7: 307-12.

[8] Moodley J, Jjuuko G, Rout C. Epidural compared with general anaesthesia for caesarean delivery in conscious women with eclampsia. Br J Obstet Gynaecol 2001; 108: 378-82.

[9] Razzaque M, Rahman K, Sashidhan R. Spinal is safer than GA for LSCS in eclamptics. Anesthesiology 2001; 94: A34.

[10] Horlocker TT, Wedel DJ, Rowlingson JC, Enneking FK, Kopp $\mathrm{SL}$ et al. Regional anesthesia in the patient receiving antithrombotic therapy: American Society of Regional Anesthesia and Pain Medicine Evidence-Based Guideline. $3^{\text {rd }}$ ed. Reg Anesth Pain Med 2010; 35: 64-101.

[11] Antonie AG, Mangin R, Vialles N, Ferrer JM, Robert C et al. Patients with severe Pre-eclampsia experience less hypotension during spinal anesthesia for elective cesarean delivery than healthy parturients: A Prospective cohort comparison. Anesth Analg 2003; 97: 867-72.

[12] Adamu AS, Bako B, El-Nafaty AU, Babagana M, Ahmed M, et al. Obstetrics admission to the intensive care unit at the Nigerian teaching hospital: a four year review. Journal of Scientific Research and Studies 2014;1(5): 81-86.

[13] Muhammad Z, Muhammad D, Ibrahim SA (2010). Obstetric admissions to the intensive care unit: A seven year review at Aminu Kano Teaching Hospital Kano, Nigeria. BOMJ. 7(1):115 .

[14] Osinaike BB, Amanor-Boadu SD, Sanusi AA. Obstetrics Admission to the Intensive Care Unit: an eight year review. Med Liban. 2008; 56 (4): 215-219.

[15] Dao B, Rouamba A, Quedrago D. Transfer of Obstetrics patients in a pregnant and postpartum condition to an intensive care unit: Eighty-two cases in Burkina Faso. Gynaecol obstet fertile. 2003; 31: 123-126

[16] Natalie YWL, Arthur CWL, Kenny KCC, Yan WW. Clinical characteristics and outcomes of obstetrics patients admitted to the Intensive Care Unit: A 10- year retrospective review. Hong Kong Med J; 16(1): 18-26. 